\title{
BIOTECHNOLOGICAL PROCESS FOR OBTAINING CITRIC AND ITACONIC ACIDS
}

\section{Ynae P. David*, Taciani S. Bella de Jesus, Gabriela C. Silveira, Lucidio C. Fardelone, Gustavo P. Valença, José} A. R. Rodrigues, Paulo J. S. Moran

\section{Abstract}

Citric and itaconic acids where obtained by submerged batch fermentation and provided good results $(0.31 \mathrm{~g} / \mathrm{Lh}-31.8 \%$ yield and $0.47 \mathrm{~g} / \mathrm{Lh}-29.1 \%$ yield, respectively). These products are very important for fine chemicals, food and pharmaceutical industries.

\section{Key words:}

biotecnological process, citric acid, itaconic acid

\section{Introduction}

Citric and itaconic acids, Image 1, are extremely important as basic products being used in the chemical, food and pharmaceutical industries ${ }^{1}$.<smiles>O=C(O)CC(O)(CC(=O)O)C(=O)O</smiles>

citric acid<smiles>C=C(CC(=O)O)C(=O)O</smiles>

itaconic acid
Image 1. Citric and itaconic acids.

In this work we report preliminary results obtained from submerged batch fermentation processes for production of these acids using fungal strains on bench scale.

\section{Results and Discussion}

In the fermentation processes the strains Aspergillus niger ATCC 11414 and Aspergillus terreus ATCC 10020 were used, which are producing the citric and itaconic acids, respectively, using peptone, yeast extract, glucose and 1 -octanol in culture media.

The fermentation processes were carried out in Infors HT - Multfors bioreactors, $48 \mathrm{~h}$ and the products were purified using the perstraction technique ${ }^{2}$. The results obtained provided good yields of citric acid $(0.31 \mathrm{~g} / \mathrm{Lh}$, $31.8 \%$ yield) and itaconic acid $(0.47 \mathrm{~g} / \mathrm{Lh}, 29.1 \%$ yield $)$, Chart 1.

Chart 1. Production of citric and itaconic acids.

\begin{tabular}{|c|c|c|c|}
\hline $\begin{array}{c}\text { Fyngal } \\
\text { (ATCC) }\end{array}$ & $\begin{array}{c}\text { Residual } \\
\text { glucose (g/L) }\end{array}$ & $\begin{array}{c}\text { Citric acid } \\
\text { (g/Lh; } \%)\end{array}$ & $\begin{array}{c}\text { Itaconic acid } \\
\text { (g/Lh; } \%)\end{array}$ \\
\hline 11414 & 13.6 & $0.31 ; 31.8$ & - \\
\hline 10020 & 5.4 & - & $0.47 ; 29.1$ \\
\hline
\end{tabular}

Image 1 shows the fermentation profile of citric and itaconic acids.

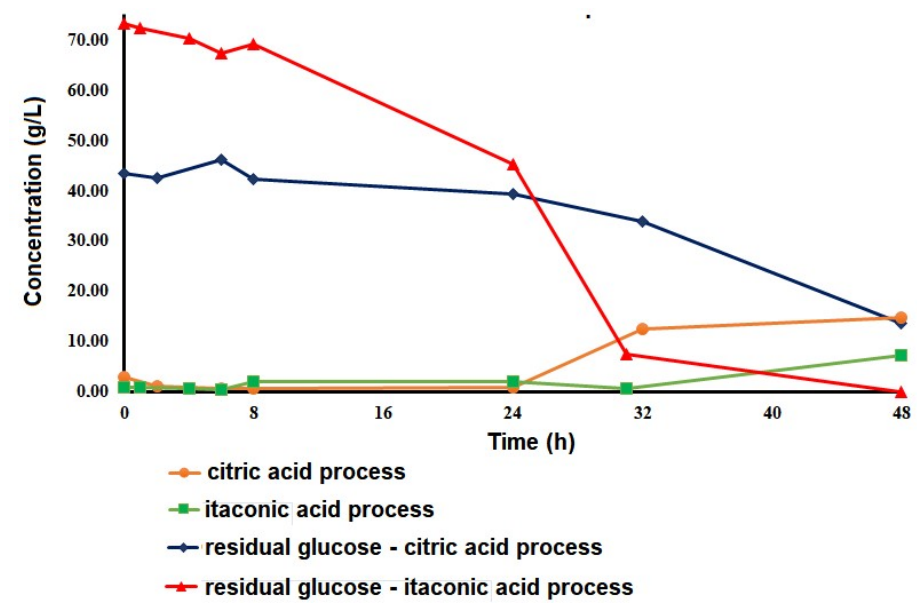

Image 1. Production of citric and itaconic acids.

\section{Conclusions}

Good yields of citric and itaconic acids production have been obtained and modifications are being carried out in the fermentation process to increase the productivity of these acids and will be reported in the future.

\section{Acknowledgement}

The authors thank FAPESP (2016/12074-7), CAPES (1643936) and CNPq for financial support.

${ }^{1}$ Bafana, R.; Pandey, R. A., Crit. Rev. Biotechnol., 2018, 38, 68.

2 Bella de Jesus, T. S.; Fardelone, L.C.; Moran, P. J. S.; Rodrigues, J. A. R.; T.

B.; Paim, G. P.; Nunhez, J. R. WO2018112577. 